\title{
Relationship Between Spatio-Temporal Leaf Area Index and Crop Coefficient When Monitoring Coffee Plots in Brazil Using the Sentine-2
}

\author{
Carolina Jaramillo-Giraldo ${ }^{1}$, Williams Pinto Marques Ferreira ${ }^{1,2}$, Humberto Paiva Fonseca ${ }^{2}$, \\ Marcelo de Freitas Ribeiro ${ }^{1}$, Laís Maria Rodrigues Silva ${ }^{3}$ \& Raphael Bragança Alves Fernandes ${ }^{3}$ \\ ${ }^{1}$ Agriculture and Livestock Research Enterprise of Minas Gerais (EPAMIG), Viçosa, MG, Brazil \\ ${ }^{2}$ National Coffee Research Center, Brazilian Corporation of Agricultural Research (EMBRAPA), Viçosa, MG, \\ Brazil \\ ${ }^{3}$ Soil Science Department, Universidade Federal de Viçosa, MG, Brazil \\ Correspondence: Carolina Jaramillo-Giraldo, Agricultural Engineering Department, Federal University of \\ Viçosa, MG 36571-000, Brazil. Tel: 55-319-9112-0021. E-mail: cuduyari@gmail.com
}

Received: May 27, 2019

doi:10.5539/jas.v11n15p187
Accepted: July 16, 2019 Online Published: September 15, 2019

URL: https://doi.org/10.5539/jas.v11n15p187

The research is financed by the Agriculture and Livestock Research Enterprise of Minas Gerais (EPAMIG) and Minas Gerais State Agency for Research Foundation (FAPEMIG).

\begin{abstract}
Robust monitoring techniques for perennial crops have become increasingly possible due to technological advances in the area of Remote Sensing (RS), and the products are available through the European Space Agency (ESA) initiative. RS data provides valuable opportunities for detailed assessments of crop conditions at plot level using high spatial, spectral, and temporal resolution. This study addresses the monitoring of coffee at the plot level using RS, analyzing the relationship between the spatio-temporal variability of the Leaf Area Index (LAI) and the crop coefficient (Kc); the Kc being a biophysical variable that integrates the potential hydrological characteristics of an agroecosystem compared to the reference crop. Daily and one-year Kc were estimated using the relation of crop evapotranspiration and reference. ESA Sentinel-2 images were pre-analyzed and atmospherically corrected, and Top-of-the-Atmosphere (TOA) reflections converted to Top-of-the-Canopy (TOC) reflectance. The TOCs resampled at the $10 \mathrm{~m}$ resolution, and with the angles corresponding to the directional information at the time of the acquisition, the LAI was estimated using the trained neural network available in the Sentinel Application Platform (SNAP). During 75\% of the monitored days, Kc ranged between 1.2 and 1.3 and, the LAI analyzed showed high spatial and temporal variability at the plot level. Based on the relationship between the biophysical variables, the LAI variable can substitute the Kc and be used to monitor the water conditions at the production area as well as analyze spatial variability inside that area. Sentinel-2 products could be more useful in monitoring coffee in the farm production area.
\end{abstract}

Keywords: crop coefficient, leaf area index, satellite crop monitoring sentinel-2

\section{Introduction}

Millions of people consume 2.25 billion cups of coffee per day and represents the value in the global market of more than $\$ 19$ billion USD. Coffee guarantees the livelihood of over 125 million people, and its production is key to 70 developing countries located between the Tropic of Cancer and the Tropic of Capricorn, the so-called 'Bean Belt' region. Brazil, Vietnam, Colombia, Ethiopia, and Indonesia are the chief producers, employing 25 million coffee farmers, mostly smallholders (Watts, 2016).

Chemura et al. (2017a) argued that the development of cost-effective, reliable and easy to implement crop condition monitoring methods are urgently required for perennial shrub crops such as coffee (Coffea arabica), as they are grown over large areas and represent long term and higher levels of investment. These monitoring methods are useful in identifying farm areas that experience weak crop growth, pest infestation and, disease outbreaks, in order to monitor responses to management interventions. 
The coffee plantations culture has generally been developed on traditionally owned plots. The plot area is relatively small, and those can be treated as a homogeneous area to the monitoring because they are typically formed by the same variety of plants, area of the same age and receive the same amount of fertilizer and the cultural treatments.

An alternative to perennial shrub coffee monitoring is the use of remote sensing tools. Particular attention has been paid to free data sources, such as those provided by the Global Monitoring for Environment and Security (GMES), an initiative of the European Space Agency (ESA). Sentinel-2 is one of the earth observation satellites used by the ESA that provides invaluable information. This satellite overcomes the problems of Landsat satellites by incorporating three new spectral bands in the red spectral region centered at 705,740 and $783 \mathrm{~nm}$, providing an improved temporal and spatial resolution of 10m (Delegido et al., 2011; Vuolo et al., 2016) which is essential for the estimation of chlorophyll content.

The Sentinel-2 current mission consists of two identical satellites, the Sentinel-2A, launched in June 2015, and the Sentinel-2B, launched in January 2017. Although released separately, the satellites were placed in the same orbit, separated by $180^{\circ}$. Every five days, the satellites together cover almost the entire land surface between latitudes $84^{\circ} \mathrm{S}$ and $84^{\circ} \mathrm{N}$, optimizing global coverage and improving temporal resolution.

Processing Sentinel-2 information is possible through the use of the Sentinel Application Platform (SNAP) software, which contains state-of-the-art tools to perform atmospheric correction processes to obtain the highest resolution of Top-of-the-Canopy (TOC) spectral reflectance. With the TOCs and a machine-learning algorithm, available in the SNAP, the monitoring of the biophysical variables of the vegetation can be realized for smallholders.

Leaf Area Index (LAI) and chlorophyll content, at canopy and plot level, are essential variables for agricultural applications because of their crucial role in photosynthesis and plant functioning (Clevers et al., 2017).

With the LAI, it is possible to define a dimensionless quantity that characterizes plant canopies. In other words, the one-sided, photosynthetically active elements of leaf area per unit ground surface area, determine the interface of the exchange of energy or mass between the canopy and atmosphere (Weiss \& Baret, 2016).

At the plot level and for various ecosystems, LAI can be considered an important parameter to analyze coffee ecosystem services (Taugourdeau et al., 2014). An increase of LAI due to shade-grown coffee interfere with the microclimate (Barradas \& Fanjul, 1986; Ong et al., 2000), evapotranspiration (Padovan et al., 2018), hydrological behavior (Gómez-Delgado et al., 2011), erosion control (Ataroff \& Monasterio, 1997), biomass and growth (Rodríguez-López et al., 2014) production (Alves et al., 2016) and net primary productivities (Defrenet et al., 2016; Charbonnier et al., 2017).

Among the variables that affect coffee development and productivity, water availability plays an important role, but it is difficult to monitor. Water management is vital in modern agriculture, particularly for perennial shrubs such as coffee. Proper detection and monitoring of soil water conditions, therefore, became essential not only in mitigating the associated adverse impacts on crop growth and productivity but also in reducing expensive and environmentally unsustainable irrigation practices (Chemura et al., 2017b). Information on crop evapotranspiration $(\mathrm{ETc})$, which represents the combined loss of water due to evaporation of the soil surface and transpiration of the crop, may facilitate better irrigation planning and, finally, water use efficiency (Akdim et al., 2014) but also improve the efficiency of cultural practices such as fertilization.

Generally, the Evapotranspiration of crops (ETc) calculations are realized by adjusting the reference evapotranspiration (ETo) by the empirical crop coefficient (Kc), i.e., ETc $=\mathrm{Kc} \times \mathrm{ETo}$. The single values of $\mathrm{Kc}$ have been estimated for different cultures (Allen et al., 1998). That calculation integrates the water consumption characteristics of the crop surface under study with those of a reference crop (usually grass) that completely covers the soil surface. The Kc varies with age, size, and spacing (Allen et al., 1998; Carr, 2001).

The aim of the present study at the plot level was to reveal the monitoring of coffee shrubs with the use of information from the Sentinel-2, through the spatial-temporal analysis of the Leaf Area Index (LAI) and the Crop Coefficient (Kc).

\section{Method}

\subsection{Characterization Site-Monitored}

The study area located in the Atlantic Rainforest biome, in the eastern portion of the State of Minas Gerais, in Southeastern Brazil, monitored in the Matas de Minas region, at an altitude of around $650 \mathrm{~m}$, between the municipalities of Viçosa and Paula Cândido (Figure 1). 

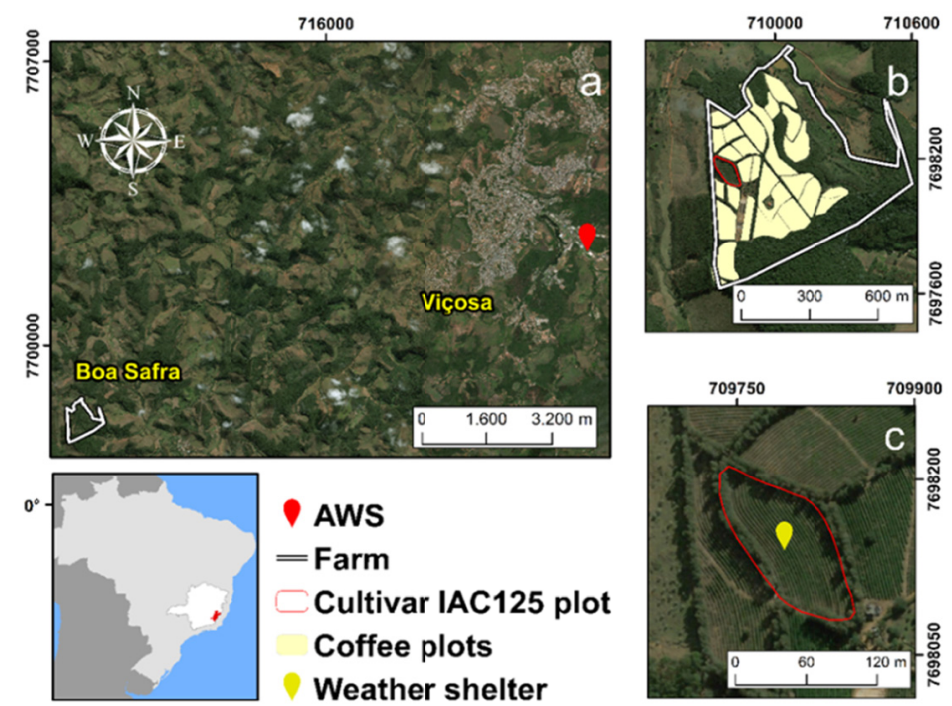

Figure 1. The Boa Safra coffee farm and the automatic weather station (AWS) in the municipality of Viçosa (a), coffee plots (b) and the plot monitored with temperature sensors in a wooden shelter (c). The images were obtained from the sensor onboard the IKONOS satellite on 2016-07-07

Arabic coffee smallholders were established in the region (Rufino et al., 2010), which has a favorable climate. The quality beverage produced there is known as "Mountain Coffee" due to its irregular topography (Ferreira et al., 2016) where the altitude ranges between 600 and 1,200 $\mathrm{m}$ (Zaidan et al., 2017). In 2016, the Instituto Brasileiro de Geografia e Estatística (IBGE) estimated that the 63 municipalities of the region have 259 thousand hectares in coffee production (IBGE, 2016).

The coffee plot $(0.57 \mathrm{ha})$ monitored uses cultivar IAC 125 . This cultivar is characterized by having low to medium size, resistance to rust, and nematodes. The coffee shrubs were planted in 2011, at the beginning of the rainy season, in a Red-Yellow Latosol of clay texture, having a density of $2.8 \mathrm{~m} \times 0.7 \mathrm{~m}$. It was uniform regarding soil attributes and slope (Table 1).

The cultural practices carried out in the coffee plot are the same as the coffee growers of the region apply to their crops, among which chemical fertilization, according to the analysis of soil and leaves, and the requirements related to the age of the crop, are carried out in the course of the rainy season and three additional applications. Control of natural vegetation was performed mechanically with brush cutters, four times a year. Due to slope, harvesting was done manually, avoiding defoliation.

The monitoring began with the rainy season of 2016 (October 12) and ended in the same month of the year of 2017, in total, 366 days. The biophysical variables, the Leaf Area Index (LAI) and the Crop Coefficient (Kc) at the plot level and point, respectively were analyzed.

\subsection{Crop Coefficient (Kc)}

The Crop Coefficient (Kc) was obtained, according to Allen et al. (1998) by the equation:

$$
K c=E T c / E T o
$$

where, ETo, ETc are the grass-reference evapotranspiration and culture $\left(\mathrm{mm} \mathrm{d}^{-1}\right)$, respectively

Daily ETo, ETc values were computed based on the equations presented by Hargreaves and Samani (1985)

$$
\text { ETo or } E T C=0.023 \times R A \times\left(T^{\circ} \mathrm{C}+17.8\right) \times T D^{0.5}
$$

where, $R A=$ extraterrestrial radiation; $T^{\circ} C$ is the daily mean temperature and $T D=\operatorname{Tm} x-\operatorname{Tmi}$ (Maximum (Tmx) and Minimum (Tmi) daily temperatures in degrees Celsius). The values of RA were calculated for each day using equations and methodologies indicated by Bojanowski (2016). 
Table 1. Coffee shrubs (cultivar IAC125) characterization and soils chemical and physical proprieties of the plot monitored

\begin{tabular}{|c|c|c|c|}
\hline Characteristics & Attributes & Depth $(\mathrm{cm})$ & IAC 125 \\
\hline \multirow{4}{*}{ Coffee shrub } & Area in hectares (ha) & & 0.57 \\
\hline & Number of stems/plot & & 3.393 \\
\hline & Age in months $\mathrm{s}^{\mathrm{a}}$ & & 69 \\
\hline & Shrubs height (m) & & 1.7 \\
\hline \multirow{16}{*}{ Chemical } & $\mathrm{pH}\left(\mathrm{H}_{2} \mathrm{O}\right)$ & $0-10$ & 6.57 \\
\hline & & $10-30$ & 6.94 \\
\hline & $\mathrm{P}\left(\mathrm{mg} / \mathrm{dm}^{-3}\right)$ & $0-10$ & 9.8 \\
\hline & & $10-30$ & 1.0 \\
\hline & $\mathrm{K}\left(\mathrm{mg} \mathrm{dm}^{-3}\right)$ & $0-10$ & 206 \\
\hline & & $10-30$ & 206 \\
\hline & $\mathrm{Ca}^{2+}$ cmolc dm $^{-3}$ & $0-10$ & 5.16 \\
\hline & & $10-30$ & 2.73 \\
\hline & $\mathrm{Mg}^{2+} \mathrm{cmolc} \mathrm{dm}^{-3}$ & $0-10$ & 1.56 \\
\hline & & $10-30$ & 0.59 \\
\hline & $\mathrm{H}+\mathrm{Al} \mathrm{cmolc} \mathrm{dm}^{-3}$ & $0-10$ & 2.6 \\
\hline & & $10-30$ & 1.4 \\
\hline & $\operatorname{CEC~(t)~cmolc~dm}{ }^{-3}$ & $0-10$ & 7.25 \\
\hline & & $10-30$ & 3.85 \\
\hline & CEC (T) cmolc dm ${ }^{-3}$ & $0-10$ & 9.85 \\
\hline & & $10-30$ & 5.25 \\
\hline \multirow[t]{7}{*}{ Physicals } & Sandy $\left(\mathrm{kg} \mathrm{kg}^{-1}\right)$ & $10-30$ & 0.31 \\
\hline & Silt $\left(\mathrm{kg} \mathrm{kg}^{-1}\right)$ & $10-30$ & 0.02 \\
\hline & Clay $\left(\mathrm{kg} \mathrm{kg}^{-1}\right)$ & $10-30$ & 0.67 \\
\hline & $\mathrm{FC}^{\mathrm{b}}\left(\mathrm{m}^{3} \mathrm{~m}^{-3}\right)$ & $0-10$ & 0.22 \\
\hline & & $10-30$ & 0.24 \\
\hline & $\operatorname{PWP}^{\mathrm{c}}\left(\mathrm{m}^{3} \mathrm{~m}^{-3}\right)$ & $0-10$ & 0.36 \\
\hline & & $10-30$ & 0.35 \\
\hline
\end{tabular}

Note. (a) Age of the crop at the beginning of the monitoring, (b) Moisture as field capacity, (c) Moisture at permanent wilting point.

To estimate the ETo, the temperature records of the Viçosa-86824 automatic meteorological station belonging to the meteorological network of the Instituto Nacional Meteorologia $5^{\circ}$ INMET, located in Viçosa-Minas Gerais, were used. The station is located less than $13 \mathrm{~km}$ from the study area (Figure 1a).

To estimate the ETc and to reduce the interference of direct solar radiation on the temperature measurement, as well as to protect the sensor from rain and insects, a wooden meteorological shelter was installed in the middle of the row of the analyzed plot (Figures $1 \mathrm{c}$ and 2). Inside this structure, at the height of $1.65 \mathrm{~m}$, data storage equipment with the HOBO U14 LCD logger Temperature/Relative Humidity (RH) sensors were installed.
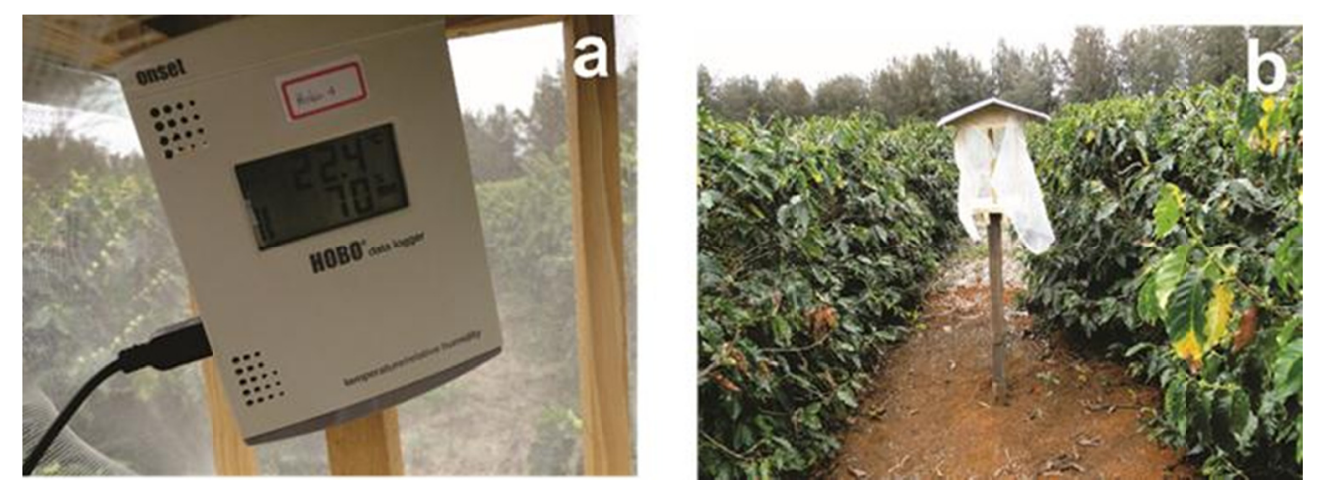

Figure 2. Temperature/Relative Humidity sensor (a) weather shelter (b) 


\subsection{Satellite Data and Leaf Area Index (LAI)}

For the present study, approximately 30 images provided by ESA were the pre-analyzed (https://scihub.copernicus.eu). Eight images were acquired because they had adequate processing conditions, such as cloudiness and/or low cloudiness.

The selected images were initially atmospherically corrected with the Sen2Cor plugin (version 2.05.05) and processed using the Sentinel Application Platform (SNAP) toolbox extension (Louis et al., 2016). The tool has excellent performance in the correction procedures due to the algorithm used, which it has on the APDA (Atmospheric Precorrected Differential Absorption). This algorithm calculates the ratio between the band B8A (Vegetation Red Edge) and the band B09 (Water Vapour) to convert the TOA to Bottom-of-Atmosphere (BOA), which represents the lower part of the atmosphere (Gascon et al., 2017).

With the BOA, we acquired the Top-of-the-Canopy (TOC) spectral reflectance, and next, we adjusted to a resolution of $10 \mathrm{~m}$. Two components, the TOCs in high resolution and with capture angles (Table 2), were the inputs to estimate the biophysical variable Leaf Area Index (LAI). Table 2 provides an overview of the Sentinel-2 images available for the coffee plot monitoring throughout the annual productive cycle (2016-2017) and the angles used as inputs in the trained neural network to estimate the LAI.

We considered that the adopted methodology is efficient. However, because of the several sources of uncertainty associated with the inputs and the algorithm calibration, we used a tolerance margin taken for the LAI product, which oscillated from 0 to 8 (Weiss \& Baret, 2016).

The LAI for each date estimated was projected in cartographic coordinates (projection UTM/WGS84). A polygon demarcated that represents the weather shelter boundaries was used to check the geometric co-registration and extraction of pixels to correlation analysis (Figure 1c).

Table 2. Specifications of Sentinel-2 overflights over the test site during the growing season of 2016-2017 in the Orbit 095.0

\begin{tabular}{lllll}
\hline Date & Solar Zenith Angle $\left({ }^{\circ}\right)$ & Solar Azimuth Angle $\left({ }^{\circ}\right)$ & View Zenith Angle $\left({ }^{\circ}\right)$ & View Azimuth Angle ( ${ }^{\circ}$ \\
\hline $2016-10-21$ & 23.41800 & 68.61480 & 2.47777 & 128.61002 \\
$2016-11-21$ & 21.03990 & 91.43230 & 2.35209 & 129.99600 \\
$2016-12-30$ & 24.84480 & 100.3300 & 2.39904 & 129.46861 \\
$2017-01-29$ & 29.76370 & 76.32980 & 2.47515 & 128.63278 \\
$2017-03-30$ & 36.29220 & 50.05490 & 2.29089 & 126.31473 \\
$2017-07-03$ & 30.32151 & 49.12548 & 2.50231 & 129.21562 \\
$2017-09-06$ & 36.88810 & 45.60660 & 2.34981 & 130.20207 \\
$2017-12-10$ & 22.59640 & 99.98620 & 2.45354 & 131.72438 \\
\hline
\end{tabular}

\subsection{Analysis of the Crop Coefficient (Kc) and the Leaf Area Index (LAI)}

In order to process the data and perform the qualitative spatial and temporal analysis of the LAI of the field monitored, as well as in the correlation analysis between the Kc and LAI variables, the functions of the libraries used were "ggplot2" (Hadley Wickham, 2009) "dplyr" (Wickham et al., 2018), "nortest" and "vcd" (Meyer et al., 2017) available in the free software R Development Core Team (2008).

\section{Results}

\subsection{Temporal Variability of the Coffee Crop Coefficient (Kc)}

The Crop Coefficient (Kc-dimensionless) of cultivar IAC 125 monitored, with temperature sensors for 366 days, presented values from 0.96 to 1.49 (average range of 0.52 ), mean of 1.24 , a variation of 0.0046 , a standard deviation of 0.068 and a coefficient of variation of $5.48 \%$. Most of the Kc values, $75 \%$, were between 1.2 to 1.3 , with a range of 0.084 (Figure 3). 


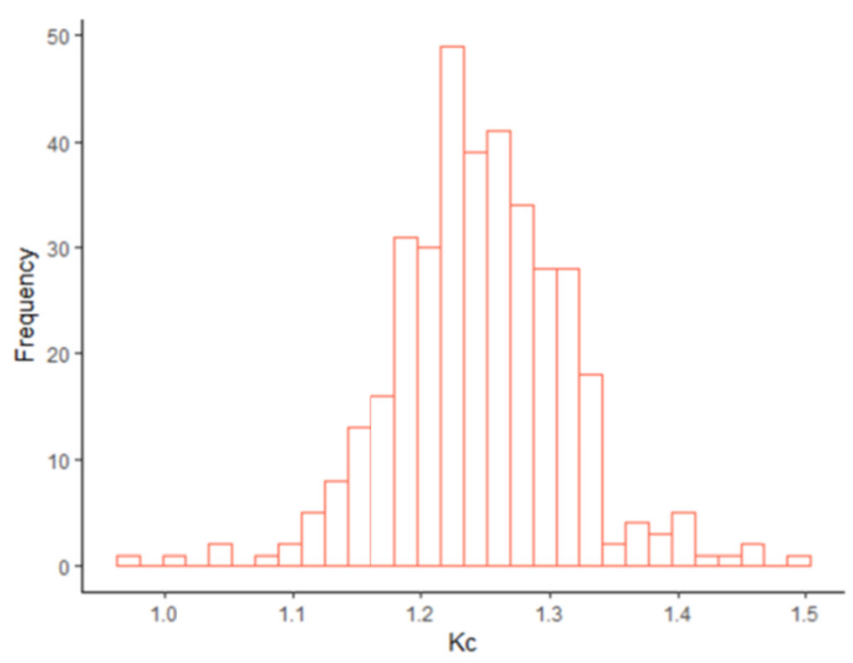

Figure 3. Crop Coefficient (Kc) estimated at the point level throughout the coffee annual productive cycle.

\subsection{Variability of the Leaf Area Index at the Plot Level}

In the eight selected images, composed of 83 pixels each (approximately 51 coffee plants per pixel), the atmospheric correction procedure was performed with the high-performance algorithm Sen2Cor (Louis et al., 2016). Given the presence of clouds determined the discard of other available images, therefore, it was not possible to process the series in uniform time intervals in the LAI monitoring. Considering the angles (Table 2) and eight corrected images as inputs to the neural network, these presented for the shrubs of coffee ranged from the highest LAI value of 5.22 to the lowest of 0.56 , with an average value of 2 .

In the first three dates evaluated, the average LAI went from 1.42 to 3.98 and reached the maximum value in the middle of the summer of 2016. Subsequently, the mean of 1.12 then increased to 2.98 in the fall of 2016. From that moment, the LAI reduced, and stabilizing in the next two dates analyzed in values of 1.98 and 1.96, arriving in the spring of 2017 with a value of 0.68 (Figure 4).

In three of the eight dates monitored (2016-11-21, 2017-01-29, 2017-03-20), the LAI pixels of the coffee plot analyzed, showed a symmetrical distribution. The other dates are asymmetric, being three (2016-10-21, 2017-07-03, 2017-09-06) with negative asymmetry and two (2016-12-30, 2017-12-10) positive. The amplitude and dispersion also vary between the monitored dates.

In the descriptive spatial analysis of LAI at the plot level (Figure 5), the total pixel population (83) per monitored date were divided into two groups: those with the lowest and highest LAI, according to the spatial variability found for each monitored period.

The lowest LAI values in all images processed were in the western part of the plot and; in seven of the eight monitored dates, the smallest LAIs located in the northwest direction; with fewer frequencies (number of pixels) in the southwest portion of the plot.

\subsection{The Relationship Between the Leaf Area Index (LAI) and the Crop Coefficient (Kc)}

For each monitored date, Table 2, the relationship between LAI and Kc were analyzed. The LAI pixels chosen correspond to the same location as the temperature sensor.

The Shapiro-Wilk and Shapiro-Francia tests $(\mathrm{p}<0.05)$ indicated that the samples of the LAI variable presented a normal distribution, whereas those of Kc did not. However, the probability graph used to compare the different forms of distribution (Figure 6) indicates that the Kc values show a higher dispersion than the theoretical one (Figure 6a) when compared to the LAI (Figure 6b) and are considered acceptable. 


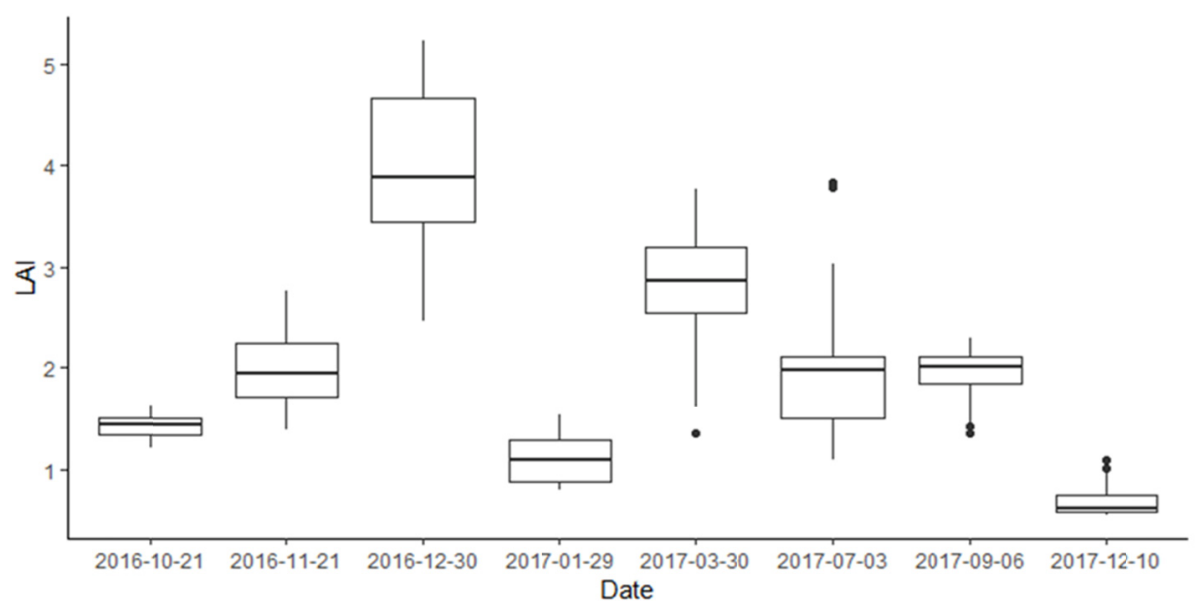

Figure 4. Leaf Area Index (LAI) monitored at the plot level throughout the annual coffee productive cycle, range and dispersion by date (yyyy-mm-dd) of LAI
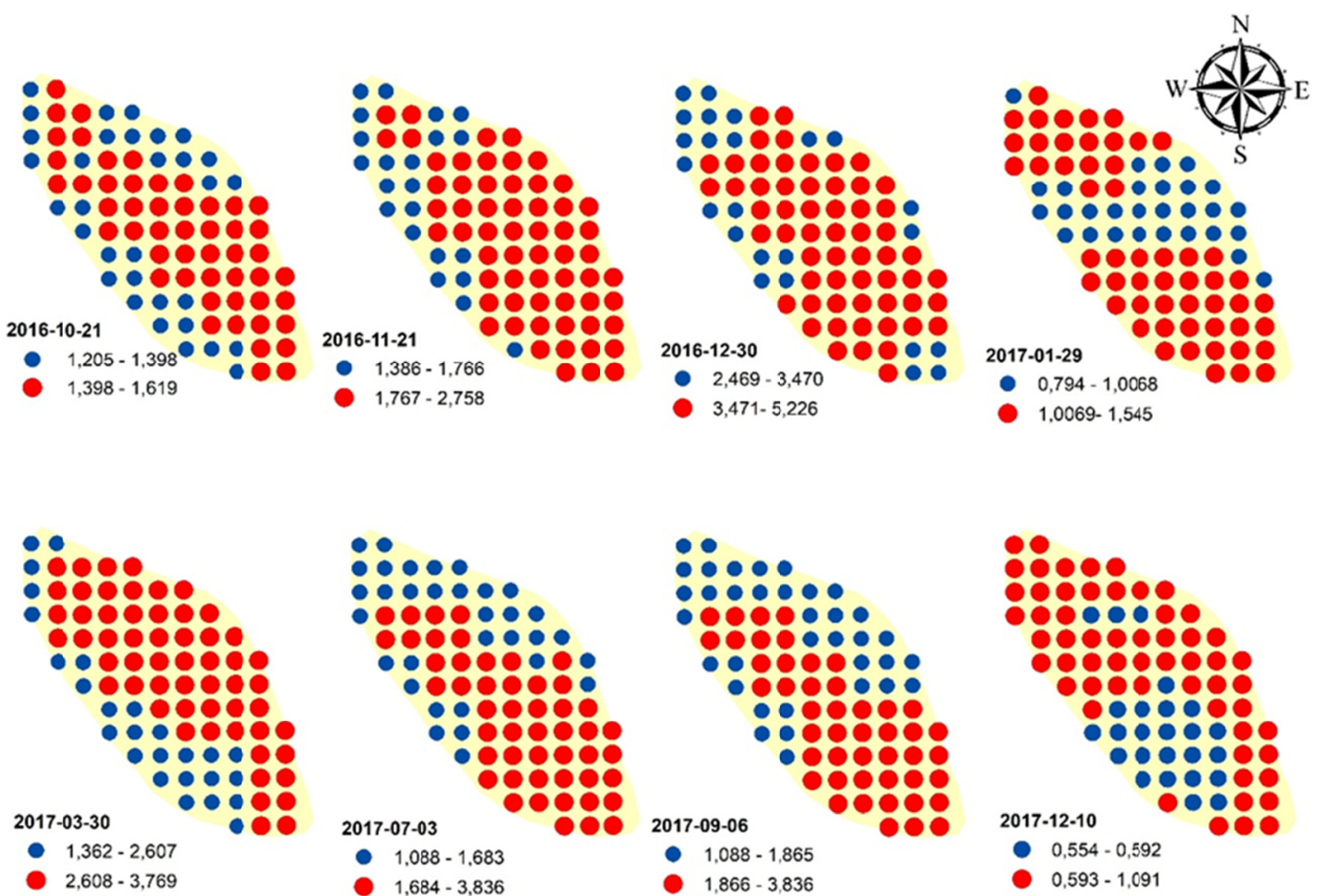

- $1,088-\mathbf{1}, 865$

$1,866-3,836$

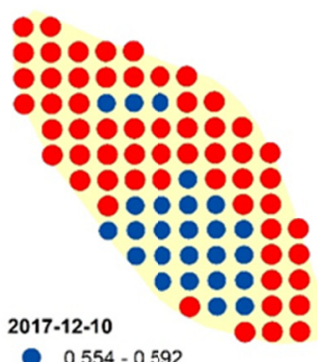

$0,554-0,592$

$0,593-1,091$

Figure 5. Spatial representation of Leaf area index (LAI) monitored at the plot level throughout the coffee annual productive cycle. Each point represents the LAI of approximate 51 shrubs 

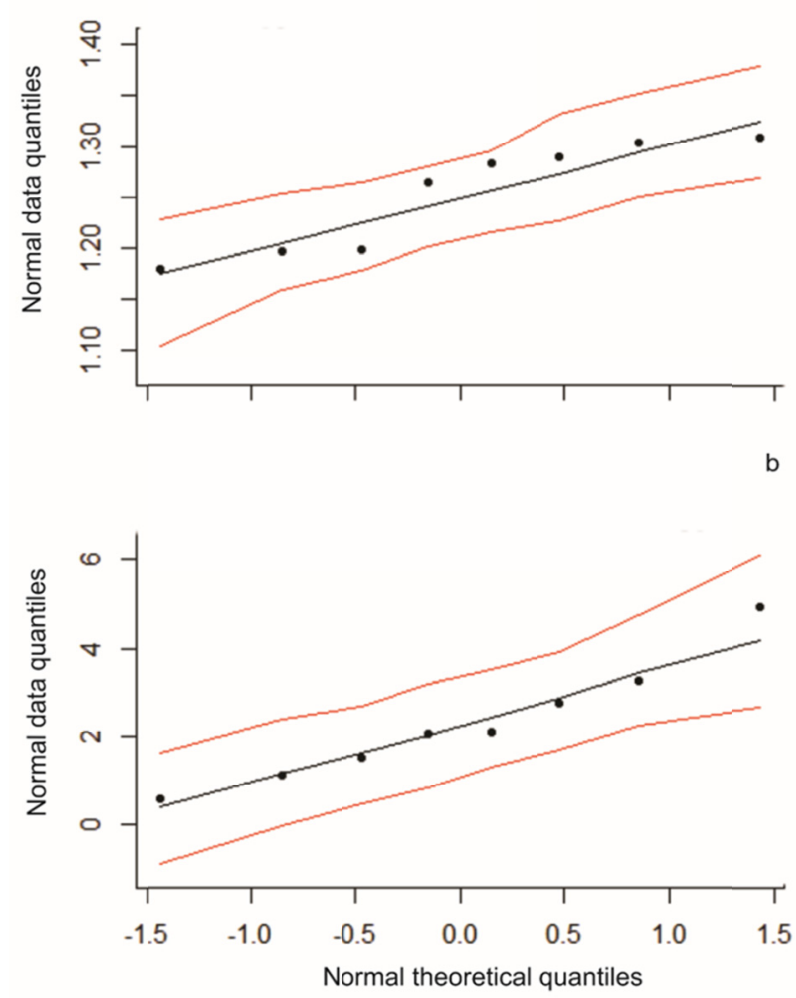

Figure 6. A normal Q-Q plot comparing randomly generated, independent standard normal data on the vertical axis: a) Crop Coefficient (Kc) and b) Leaf Area Index (LAI), to a standard normal population on the horizontal axis. The linearity of the points suggests that the data are normally distributed

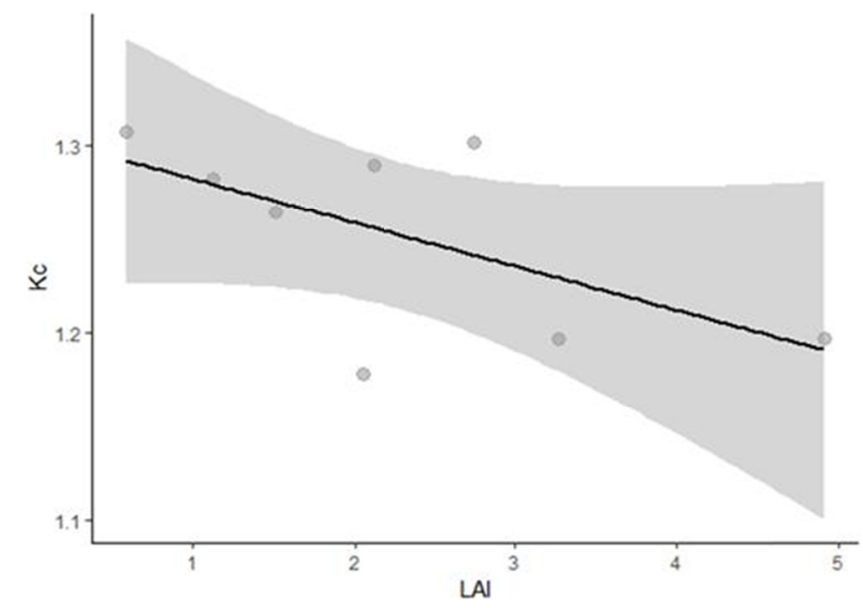

Figure 7. Scatter graph of the Leaf Area Index (LAI) and Crop Coefficient (Kc)

As the null hypothesis of normality in one of the variables rejected, the relationship between the LAI and Kc used the Spearman (rho) and Kendall (tau) rank correlation coefficient, both to determine the monotonic relationship between paired data and to verify if there is a correlation between the two variables. According to the significant tests $(0.05)$ performed ( $r h o=-0.45$ and tau $=-0.36$ ), the negative correlation was plotted in the dispersion diagram (Figure 7).

\section{Discussion}


In the 2017/2018 coffee-harvest, the monitored plot showed a yield of 38.5 bags of $60 \mathrm{~kg}$ per hectare; these are considered higher than the average of the Mata-MG region $\left(26.34 \mathrm{scs} \mathrm{ha}^{-1}\right)(\mathrm{Conab}, 2018)$. The above indicates that the nutritional corrections of the crop and agronomic treatments were carried out efficiently.

Using a weather shelter with temperature sensors inside the plot was a practical and economical option for daily variable monitoring compared to complete automatic weather stations (EMAs). The latter are instruments permanently exposed to biological activity (bees hives, spider nets or sensor shading by Leaf growth) generating faults or errors. The shelter guaranteed the series of continuous records for the calculation of crop evapotranspiration by the Hargreaves method and then analyzed the temporal variability of the coffee crop coefficient $(\mathrm{Kc})$.

The Kc values obtained in this study are consistent with those found in the literature for coffee crops (Doorenbos \& Pruitt, 1977; Allen et al., 1998; Villa Nova et al., 2002; Marin et al., 2005; Oliveira et al., 2007; Sato et al., 2007; Pereira et al., 2011; Flumignan et al., 2011).

For coffee shrubs with a height of $2 \mathrm{~m}$ to $3 \mathrm{~m}$ (Allen et al., 1998), indicated the value of Kc from 0.90 to 0.95 and from 1.05 to 1.10 in the bare ground cover and with weeds, respectively. However, this estimation is applied to sub-humid climate. Besides, Doorenbos and Pruitt (1977) indicated for mature coffee grown without shade and where cultural practices involve clean cultivation with heavy cut grass mulching, Kc of around 0.9 is recommended throughout the year. If significant weed growth is allowed, coefficients close to 1.05-1.1 would be more appropriate. However, in the results of the present study, in $75 \%$ of the 366 days of monitored temperature, $\mathrm{Kc}$ (one year of evaluation) ranged from 1.2 to 1.3 .

In Brazil, the leading coffee producing country in the world, experiments to determine the crop coefficient for the improvement of cultural practices such as irrigation, are scarce. Irrigated coffee cultivation has become an essential practice since 1984, favoring the implementation of crops in areas that have water or marginal deficits, but most of the studies conducted only verify the increase in production or test irrigation methods (Mantovani et al., 2007).

The studies published of Kc in irrigated coffee include those of Flumignan et al. (2011), Marin et al. (2005), Oliveira et al. (2007), Pereira et al. (2011) and others related with cultural practices or growth of the culture carried out and published by Villa Nova et al. (2002) and Sato et al. (2007).

In the publication of Villa Nova et al. (2002) argued that coffee crops between 12 and 36 months of age could have Kc ranging from 0.8 to 1.1. On the other hand, those older than 36 months, Kc values can range from 1.0 to 1.3. Also, the authors point out that at a density of 2,500 plants per hectare, the Kc can be 0.8 , and for 6,666 plants per hectare, the Kc can be 1. According to Sato et al. (2007), after four years of pruning the coffee had Kc values ranging from 0.59 to 1.16 .

Marin et al. (2005) characterized the water used by the coffee shrub in the drip irrigation system and estimated with a net radiometer (Kipp \& Zonen sensors) the Kc value. The results of Kc showed a range from 0.6 to 1.9 and average 1, throughout the monitoring. Another study evaluating the irrigation management system for the 36-month-old coffee in the State of Goiás revealed Kc values ranging from 0.92 to 1.51 Oliveira et al. (2007). Also, the study by Flumignan et al. (2011), presented Kc results from 0.5 to 1.5 in three-year-old coffee shrubs grown on weighing lysimeter and different irrigation systems (spraying and dripping).

Experimental results indicate that Kc depends on several factors characteristic of the coffee shrub, including the stage of growth of vegetation, plant density, row spacing, and canopy architecture and/or cultural practices; the presence of the spontaneous plants between the rows of the crop alter the values of Kc (Allen et al., 1998; Villa Nova et al., 2002; Pereira et al., 2015).

Flumignan et al. (2011) also argued that the study presents discrepancies between Kc values of coffee according to the factors mentioned, besides the number of evaluation days and their distribution throughout the year, irrigation management or methodologies used to determine evapotranspiration (ET).

In Brazil, due to the territorial extension, wide climatic variability, diversity of production systems and coffee irrigation methods, it is necessary to quantify the water needs of the crop and to ensure the correct irrigation management through dynamic monitoring.

The size of the vegetation transpiration surface can be related to the leaf area since the leaves are the primary organs that participate in the transpiratory process, responsible for the gas exchange with the environment. On the other hand, at the plot level, the loss of water from the crop can be represented by the Leaf Area Index (LAI), which is defined as the ratio between the leaf area (one side only of the leaf) and the area of land occupied by the 
crop. Thus, LAI is dimensionless and expresses the relative size of the leaf area when in competition for natural resources (water, nutrients, and light) (Pereira et al., 2008).

Leaf Area Index is a parameter that is difficult to measure but very useful. Most studies use destructive methods to quantify LAI, Coltri et al. (2015). In this study, the LAI at the plot-monitored level over eight dates during one year, the results representing the temporal and spatial variation of the variable. The trained neural network provided LAI values ranging from 0.6 to 5.6.

The study of Coffee LAI, a parameter derived from MODIS sensor (Moderate Resolution Imaging Spectroradiometer) realized by Taugourdeau et al. (2014) in the central Caribbean region, reports that the seasonal variation of the LAI ranged from 2.4 to 4.4. The authors indicate that, for perennial crops such as coffee, LAI may vary seasonally due to abiotic factors such as drought, shade, temperatures, and biological factors, such as diseases and overproduction, or even by pruning or fertilization. Brazilian studies that periodically evaluated LAI values using allometric measurements indicated results from 0.27 to 2.98 (Pereira et al., 2011) and from 2.3 to 8.7 (Flumignan et al., 2011).

Pereira et al. (2011) report that the LAI increases linearly as the coffee grows. On the other hand, Flumignan et al. (2011) reported that LAI showed large oscillations throughout the measurements in all treatments evaluated with irrigated, non-irrigated and controlled and that tendency was observed in the present study (Figure 4). To Flumignan et al. (2011) the empirical IAF for the control treatment, in coffee plants with an approximate age of 36 months, went from 2.7 to 4.7 , and in the following months, it decreased and reduced to values below 2.7 , and later, in the LAI again increased.

According to Carr (2001), water stress reduced the total leaf area of container-grown plants and explained that there is much evidence of the sensitivity of coffee stomatal conductance to the prevailing atmospheric conditions and in principal are high total irradiance $\left(1000 \mathrm{~W} \mathrm{~m}^{-2}\right)$, air temperature $\left(26-30{ }^{\circ} \mathrm{C}\right)$ and saturation deficit $(>1.6$ $\mathrm{kPa}$ ) These are conditions where the stomata remained closed all day.

In Brazil, coffee grows actively from the first rains of the year, which occur between September and October. During this period, vegetative growth happens at the rate of 1.1 leaves per month, peaking in the summer, with 1.6 leaves per month. Then, with the reduction of rainfall and temperature (in addition to the nutritional effect and photoperiod), the plant rests, growing at only 0.5 pairs of leaves per month (Matiello et al., 2015). This seasonal variability may also influence the LAI values.

Also sometimes some periods in a year, the locally measured coffee shrub experience higher soil evaporation (E) than leaf area transpiration $(\mathrm{T})$ and $\mathrm{Kc}$ serves the critical purpose of representing averaged $\mathrm{E}$ and $\mathrm{T}$ process (Pereira et al., 2015b). In this work, the negative correlation between the two biophysical variables analyzed (Figure 7) may be acceptable (or reasonable) since the estimated Kc values by Allen et al. (1998); Doorenbos and Pruitt (1977); Flumignan et al. (2011); and Sato et al. (2007); and the LAI values by Taugourdeau et al. (2014); Pereira et al. (2011) were consistent with the results.

Monitoring the LAI at the plot level with Sentinel-2 products makes it possible to understand the state of the coffee as a whole. In this study, the LAI spatial variability analysis indicated that the lowest values were found at specific sites during monitoring (Figure 5), which are probably related to soil variability or deficiency of some mineral elements such as boron. Currently more monitoring time is required to confirm this trend.

The Sentinel-2 products are of quality, with an excellent spatial resolution of $10 \mathrm{~m}$. They can monitor approximately 51 coffee shrubs per pixel, but they demand high computational capacity and data storage, beside technical personnel prepared for the processing and interpretation that, for coffee smallholders, is not easily accessed.

\section{Conclusions}

Sentinel-2 products make it possible to monitor the coffee crop at the plot level. The relationship between Leaf Area Index (LAI) and Crop Coefficient $(\mathrm{Kc})$ indicates that LAI can be used to monitor crop water conditions. The use of the LAI in substitution for Kc makes it possible to identify the state of the coffee tree regarding age, spacing, natural vegetation as well as the variability of the plot, having a more reliable estimate of the available water conditions for the crop.

\section{Acknowledgements}

This study was supported by Minas Gerais State Agency for Research Foundation (FAPEMIG) for the provision of a scholarship for a visiting researcher, which mades this work feasible. Agriculture and Livestock Research 
Enterprise of Minas Gerais (EPAMIG) for the concession of its facilities for the execution of the research and the Embrapa-Café for the partnership accomplished through the academic orientation exercised.

\section{References}

Akdim, N., Alfieri, S. M., Habib, A., Choukri, A., Cheruiyot, E., Labbassi, K., \& Menenti, M. (2014). Monitoring of irrigation schemes by remote sensing: Phenology versus retrieval of biophysical variables. Remote Sensing, 6(6), 5815-5851. https://doi.org/10.3390/rs6065815

Allen, R. G., Pereira, L. S., Raes, D., \& Smith, M. (1998). Crop evapotranspiration-Guidelines for computing crop water requirements-FAO Irrigation and drainage paper 56. Rome, Food and Agriculture Organization of the United Nations.

Alves, V., Goular, F. F., Jacobson, T. K. B., Filho, R. J. D. E. M., \& Ribas, C. E. D. C. (2016). Shade's benefit: Coffee production under shade and full sun. Journal of Agricultural Science, 8(11). https://doi.org/ 10.5539/jas.v8n11p11

Ataroff, M., \& Monasterio, M. (1997). Soil erosion under different management of coffee plantations in the Venezuelan Andes. Soil Technology, 11, 95-108. https://doi.org/10.1016/S0933-3630(96)00118-3

Barradas, V. L., \& Fanjul, L. (1986). Microclimatic chacterization of shaded and open-grown coffee (Coffea arabica L.) plantations in Mexico. Agricultural and Forest Meteorology, 38, 101-112. https://doi.org/ 10.1016/0168-1923(86)90052-3

Bojanowski, J. S. (2016). Sirad: Functions for calculating daily solar radiation and evapotranspiration (R package Version 2.3-3). Retrieved from https://cran.r-project.org/web/packages/sirad/sirad.pdf

Carr, M. K. V. (2001). The water relations and irrigation requirements of coffee. Experimental Agriculture, 37, 1-36. https://doi.org/10.1017/S0014479701001090

Charbonnier, F., Roupsard, O., le Maire, G., Guillemot, J., Casanoves, F., Lacointe, A., ... Dreyer, E. (2017). Increased light-use efficiency sustains net primary productivity of shaded coffee plants in agroforestry system. Plant Cell and Environment, 40, 1592-1608. https://doi.org/10.1111/pce.12964

Chemura, A., Mutanga, O., \& Dube, T. (2017a). Integrating age in the detection and mapping of incongruous patches in coffee (Coffea arabica) plantations using multi-temporal Landsat 8 NDVI anomalies. International Journal of Applied Earth Observation and Geoinformation, 57, 1-13. https://doi.org/10.1016/ j.jag.2016.12.007

Chemura, A., Mutanga, O., \& Dube, T. (2017b). Remote sensing leaf water stress in coffee (Coffea arabica) using secondary effects of water absorption and random forests. Physics and Chemistry of the Earth, 100, 317-324. https://doi.org/10.1016/j.pce.2017.02.011

Clevers, J., Kooistra, L., van den Brande, M., Clevers, J. G. P. W., Kooistra, L., \& van den Brande, M. M. M. (2017). Using Sentinel-2 Data for Retrieving LAI and Leaf and Canopy Chlorophyll Content of a Potato Crop. Remote Sensing, 9(5), 405. https://doi.org/10.3390/rs9050405

Coltri, P. P., Zullo Junior, J., Dubreuil, V., Ramirez, G. M., Pinto, H. S., Coral, G., \& Lazarim, C. G. (2015). Empirical models to predict LAI and aboveground biomass of Coffea arabica under full sun and shaded plantation: A case study of South of Minas Gerais, Brazil. Agroforestry Systems, 89(4), 621-636. https://doi.org/10.1007/s10457-015-9799-5

CONAB (Companhia Nacional de Abastecimento). (2018). Acompanhamento da safra brasileira: Café (V5 n-2, 66). Retrieved from https://www.conab.gov.br/info-agro/safras/cafe

Defrenet, E., Roupsard, O., Van den Meersche, K., Charbonnier, F., Pérez-Molina, J. P., Khac, E., ... Jourdan, C. (2016). Part of a special issue on root biology: Root biomass, turnover and net primary productivity of a coffee agroforestry system in Costa Rica: Effects of soil depth, shade trees, distance to row and coffee age. Annals of Botany, 118(4), 833-851. https://doi.org/10.1093/aob/mcw153

Delegido, J., Verrelst, J., Alonso, L., \& Moreno, J. (2011). Evaluation of Sentinel-2 red-edge bands for empirical estimation of green LAI and chlorophyll content. Sensors, 11(7), 7063-81. https://doi.org/10.3390/ s1 10707063

Doorenbos, J., \& Pruitt, W. (1977). Crop Water Requirements (FAO Irrigation and Drainage Paper No. 24). Rome, Food and Agriculture Organization of the United Nations. 
Ferreira, W. P. M., Queiroz, D. M., Silvac, S. A., Tomaz, R. S., \& Corrêa, P. C. (2016). Effects of the Orientation of the Mountainside, Altitude and Varieties on the Quality of the Coffee Beverage from the "Matas de Minas" Region, Brazilian Southeast. American Journal of Plant Sciences, 7, 1291-1303. https://doi.org/10.4236/ajps.2016.78124

Flumignan, D. L., de Faria, R. T., \& Prete, C. E. C. (2011). Evapotranspiration components and dual crop coefficients of coffee trees during crop production. Agricultural Water Management, 98, 791-800. https://doi.org/10.1016/J.AGWAT.2010.12.002

Gascon, F., Bouzinac, C., Thépaut, O., Jung, M., Francesconi, B., Louis, J., ... Fernandez, V. (2017). Copernicus Sentinel-2A calibration and products validation status. Remote Sensing, 9(6), 584. https://doi.org/ 10.3390/rs9060584

Gómez-Delgado, F., Roupsard, O., Le Maire, G., Taugourdeau, S., Pérez, A., Van Oijen, M., ... Moussa, R. (2011). Modelling the hydrological behaviour of a coffee agroforestry basin in Costa Rica. Hydrology and Earth System Sciences, 15, 369-392. https://doi.org/10.5194/hess-15-369-2011

Hargreaves, G. H., \& Samani, Z. A. (1985). Reference Crop Evapotranspiration from Temperature. Applied Engineering in Agriculture, 1(2), 96-99. https://doi.org/10.13031/2013.26773

IBGE (Instituto Brasileiro de Geografia e Estatística). (2016). Culturas temporárias e permanentes-Estatísticas. Retrieved from https://www.ibge.gov.br/estatisticas-novoportal/economicas/agricultura-e-pecuaria/9117-pr oducao-agricola-municipal-culturas-temporarias-e-permanentes.html? $=\& \mathrm{t}=\mathrm{o}-\mathrm{que}-\mathrm{e}$

Louis, J., Debaecker, V., Pflug, B., Main-Knorn, M., Bieniarz, J., Mueller-Wilm, U., ... Gascon, F (2016). Sentinel-2 SEN2COR: L2A processor for user. Paper presented at the Living Planet Symposium 2016, Prague, Czech Republic.

Mantovani, E. C., Vicente, M. R., Alves, M. E. B., \& Neto, H. B. (2007). Irrigação como fator de qualidade do café. In L. Zambolim (Ed.), Boas Práticas Agrícolas Na Produção de Café (pp. 117-166). Viçosa, Minas Gerais.

Marin, F. R., Angelocci, L. R., Righi, E. Z., \& Sentelhas, P. C. (2005). Evapotranspiration and irrigation requirements of a coffee plantation in southern Brazil. Experimental Agriculture, 41, 187-197. https://doi.org/10.1017/S0014479704002480

Matiello, J. B., Santinato, R., Almeida, S. R., \& Garcia, R. A. W. (2015). Cultura de Café No Brasil. Manual de Recomendações (2nd ed.). Varginha, MG: Fundação Procafé.

Meyer, D., Zeileis, A., \& Hornik, K. (2017). Visualizing Categorical Data (R Package Version 1.4-4). Retrieved from https://cran.r-project.org/web/packages/vcd/vcd.pdf

Oliveira, L. F. C., Oliveira, R. Z., Borges, L. B., Wehr, T. R., \& Bonomo, R. (2007). Coeficiente de cultura e relações hídricas do cafeeiro, cultivar catucaí, sob dois sistemas de manejo da irrigação. Pesquisa Agropecuária Tropical, 37, 154-162.

Ong, C. K., Black, C. R., Wallace, J. S., Khan, A. A. H., Lott, J. E., Jackson, N. A., .. Smith, D. M. (2000). Productivity, microclimate and water use in Grevillea robusta-based agroforestry systems on hillslopes in semi-arid Kenya. Agriculture, Ecosystems and Environment, 80, 121-141. https://doi.org/10.1016/ S0167-8809(00)00144-4

Padovan, M. P., Brook, R. M., Barrios, M., Cruz-Castillo, J. B., Vilchez-Mendoza, S. J., Costa, A. N., \& Rapidel, B. (2018). Water loss by transpiration and soil evaporation in coffee shaded by Tabebuia rosea Bertol. and Simarouba glauca DC. compared to unshaded coffee in sub-optimal environmental conditions. Agricultural and Forest Meteorology, 248, 1-14. https://doi.org10.1016/j.agrformet.2017.08.036

Pereira, L. S., Allen, R. G., Smith, M., \& Raes, D. (2015). Crop evapotranspiration estimation with FAO56: Past and future. Agricultural Water Management, 147, 4-20. https://doi.org/10.1016/j.agwat.2014.07.031

Pereira, A. R., De Camargo, Â. P., \& De Camargo, M. B. P. (2008). In O. G. Filho, R. M. Coelho, \& C. A. F. P. Maglio (Eds.), Agrometeorologia Dos Cafezais No Brasil. Campinas-São Paulo.

Pereira, A. R., De Camargo, M. B. P., \& Villa Nova, N. A. (2011). Coffee crop coefficient for precision irrigation based on leaf area index. Bragantia, 70, 946-951. https://doi.org/10.1590/S0006-87052011000 400030

R Development Core Team. (2008). R: A language and environment for statistical computing. Retrieved from http://www.r-project.org 
Rodríguez-López, N. F., Martins, S. C. V., Cavatte, P. C., Silva, P. E. M., Morais, L. E., Pereira, L. F., ... da Matta, F. M. (2014). Morphological and physiological acclimations of coffee seedlings to growth over a range of fixed or changing light supplies. Environmental and Experimental Botany, 102, 1-10. https://doi.org/ 10.1016/j.envexpbot.2014.01.008

Rufino, dos S. J. L., Silveira, de S. V., \& Ribeiro, R. C. A. (2010). Cafeicultura de Montanha-Minas Gerais. Caracterização da cafeicultura de montanha de Minas Gerais. Retrieved from http://www.sistemafaemg. org.br/web/files/1791326436247148171218200173247190199432722.pdf

Sato, F. A., Da Silva, A. M., Coelho, G., Da Silva, A. C., \& De Carvalho, L. G. (2007). Coeficiente de cultura $(\mathrm{kc})$ do cafeeiro (Coffea arabica) no período de outono-inverno na região de Lavras-MG. Engenharia Agricola, 27(2), 383-391. https://doi.org/10.1590/S0100-69162007000300007

Taugourdeau, S., le Maire, G., Avelino, J., Jones, J. R., Ramirez, L. G., Jara Quesada, M., ... Roupsard, O. (2014). Leaf area index as an indicator of ecosystem services and management practices: An application for coffee agroforestry. Agriculture, Ecosystems \& Environment, 192, 19-37. https://doi.org/10.1016/ J.AGEE.2014.03.042

Villa Nova, N. A., Favarin, J. L., Angelocci, L. R., \& Dourado-Neto, D. (2002). Estimativa do coeficiente de cultura do cafeeiro em função de variáveis climatológicas e fitotécnicas. Bragantia, 61, 81-88. https://doi.org/10.1590/S0006-87052002000100013

Vuolo, F., Żółtak, M., Pipitone, C., Zappa, L., Wenng, H., Immitzer, M., ... Atzberger, C. (2016). Data Service Platform for Sentinel-2 Surface Reflectance and Value-Added Products: System Use and Examples. Remote Sensing, 8, 938. https://doi.org/10.3390/rs8110938

Watts, C. (2016). The Climate Change Risks to Coffee A Brewing Storm: The Climate Change Risks to Coffee. The Climate Institute. Retrieved from http://fairtrade.com.au/ /media/fairtrade\%20australasia/files/resour ces $\% 20$ for $\% 20$ pages $\% 20-\% 20$ reports $\% 20$ standards $\% 20$ and $\% 20$ policies/tci_a_brewing_storm_final_24082 016_web.pdf

Weiss, M., \& Baret, F. (2016). S2ToolBox Level 2 Products: LAI, FAPAR, FCOVER Version 1.1. Retrieved from http://step.esa.int/docs/extra/ATBD_S2ToolBox_L2B_V1.1.pdf

Wickham, H. (2009). Ggplot2: Elegant Graphics for Data Analysis (2nd ed.). New York, NY: Springer-Verlag. https://doi.org/10.1007/978-0-387-98141-3

Zaidan, Ú. R., Corrêa, P. C., Ferreira, W. P. M., Cecon, P. R., \& Cecon, P. R. (2017). Ambiente e variedades influenciam a qualidade de cafés das matas de minas. Coffee Science, 12, 240. https://doi.org/10.25186/ cs.v12i2.1256

\section{Copyrights}

Copyright for this article is retained by the author(s), with first publication rights granted to the journal.

This is an open-access article distributed under the terms and conditions of the Creative Commons Attribution license (http://creativecommons.org/licenses/by/4.0/). 